\title{
La construcción discursiva de la militancia juvenil en la Argentina kirchnerista. El caso de La Cámpora
}

\author{
Rocío Flax - Universidad de Buenos Aires /CONICET \\ rocioflax@educ.ar
}

Rebut / Received: 19-10-15

Acceptat / Accepted: 12-4-16

Resum. La construcció discursiva de la militància juvenil a l'Argentina kirchnerista. el cas de La Cámpora. A l'Argentina, en els últims anys s'ha experimentat una revitalització de la militància juvenil, especialment dins del moviment kirchnerista. La pregunta que ens mou en aquest treball en particular és: com expliquen els propis militants el sorgiment d'una agrupació juvenil massiva dins el kirchnerisme? Ens proposem analitzar quines raons construeixen els membres d'aquesta agrupació per explicar aquest fenomen i per què consideren el kirchnerisme com l'espai adequat perquè es desenvolupi. La hipòtesi que presentem és que reprodueixen les representacions hegemòniques a Argentina que postulen una completa inactivitat política juvenil durant la dècada neoliberal dels 90, seguida d'una irrupció militant en els últims anys. La condició per a aquesta irrupció seria la convocatòria a la joventut i la resignificació de la política desenvolupada pel kirchnerisme, projecte que representaria valors oposats a aquells que imperaven durant les presidències de Carlos Menem, entre els anys 1989 i 1999.

Paraules clau: anàlisi del discurs, discurs polític, joventut, identitat, representacions socials.

Abstract. The discursive construction of political activism in the Argentina of kirchnerism. The case of La Cámpora. In Argentina, it has been experienced a revitalization of youth activism in recent years, especially in the kirchnerist movement. The question that moves us in this particular job is: how the activists themselves explain the emergence of a massive group of young people within the kirchnerism? We analyze what reasons their members build to explain this phenomenon and why they consider kirchnerism as the adequate space for its development. The hypothesis presented is that they reproduce the hegemonic representations in Argentina 
that postulates a political inactivity from young people during the neoliberal decade of the ' 90 , followed by an activist irruption in recent years. The condition for that irruption would be the call to the youth and the redefinition of politics developed by the kirchnerism, a project that would represent opposite values to those that prevailed during the presidencies of Carlos Menem, between 1989 and 1999 .

Keywords: discourse analysis, political discourse, youth, identity, social representations.

\section{Introducción}

En Argentina, en los últimos años se ha experimentado una revitalización de la militancia juvenil (Kriger, 2011), en especial dentro del movimiento kirchnerista. El presente artículo se inscribe en el marco de una investigación que busca comprender, desde una perspectiva lingüístico-discursiva, la especificidad de la construcción, desarrollo y afianzamiento de La Cámpora, una agrupación política juvenil que fue gestada desde el Estado, durante los gobiernos de Néstor Kirchner y Cristina Fernández.

La pregunta que nos mueve en este trabajo en particular es: ¿cómo explican los propios militantes el surgimiento de una agrupación juvenil masiva como La Cámpora? Nos proponemos analizar qué razones construyen sus miembros para explicar este fenómeno y por qué consideran al kirchnerismo como el espacio adecuado para su desarrollo. La hipótesis que presentamos es que reproducen las representaciones hegemónicas en Argentina que postulan una completa inactividad política juvenil durante la década neoliberal del 90, seguida de una irrupción militante en los últimos ańos (Kriger, 2011; Bonvillani, Palermo, Vázquez y Vommaro, 2010). La condición para esa irrupción sería la convocatoria a la juventud y la resignificación de la política desarrollada por el kirchnerismo, proyecto que representaría valores opuestos a aquellos que imperaban durante las presidencias de Carlos Menem, entre los años 1989 y 1999.

Nuestro marco teórico es el Análisis Crítico del Discurso (Fairclough, 2003a, 2003b, 2005; van Leeuwen, 2008; van Dijk, 2005) y utilizamos las herramientas de análisis de la Lingüística Crítica (Fowler, Hodge, Kress y Trew, 1983; Hodge y Kress, 1979) y de la Teoría de la Valoración (Martin y White, 2005; Kaplan, 2004).

\section{Marco teórico y metodología}

El Análisis Crítico del Discurso (Fairclough, 2003a, 2003b, 2005; Fairclough y Wodak, 2000; van Leeuwen, 2008) considera que el uso del lenguaje no es un simple efecto o reflejo de los procesos sociales y de la organización social: es parte del proceso social y, por lo tanto, constituye significaciones y prácticas. En este sentido, los discursos construyen y expresan las representaciones y creencias de los hablantes y, en consecuencia, 
influyen en sus actitudes y decisiones. Los discursos no envuelven solamente un campo de objetos, sino también una definición de una perspectiva legítima para el agente de conocimiento en un determinado contexto (van Leeuwen, 2008). Es decir, no solo representan lo que sucede, sino que lo evalúan, le adscriben propósitos, lo legitiman o deslegitiman. Y todos estos aspectos son mucho más importantes que la representación misma de la práctica.

Fairclough (1992, 2003a, 2003b, 2005) considera que todo fenómeno discursivo posee tres dimensiones interrelacionadas: constituye una práctica social, una práctica discursiva y una práctica textual. La dimensión del texto se refiere al análisis lingüístico propiamente dicho. El texto es la materialidad en que se realizan las prácticas discursivas. La dimensión de la práctica discursiva se ocupa del aspecto interactivo del discurso, analiza las condiciones de producción e interpretación. La dimensión de la práctica social se ocupa del análisis social de los aspectos institucionales o las circunstancias organizacionales y como esos aspectos dan forma a la práctica discursiva (y viceversa). El punto de partida del Análisis Crítico no son las prácticas discursivas, sino las prácticas sociales, entre las cuales están incluidos los discursos. Sin embargo, el análisis lingüístico concreto comienza por la práctica textual, entendida como su materialidad semiótica.

Para el análisis de la práctica textual, se utiliza el modelo de análisis de la Lingüística Crítica (Hodge y Kress, 1979; Fowler et al., 1983).Esta corriente considera al lenguaje como un conjunto relacionado de categorías y procesos. Un proceso es aquello que posee una dimensión temporal, es decir, los verbos — conjugados o en sus formas no finitaspero también las nominalizaciones. Las categorías se pueden relacionar de distintas formas con los procesos. Se las va a llamar participantes y pueden ser actores, afectados, circunstancias o pueden estar relacionados con otros objetos (entidades relacionantes).

La cláusula típica está formada por dos participantes vinculados entre sí por un proceso. Estas cláusulas, denominadas transactivas, se caracterizan porque uno de sus participantes ocupa el rol de actor y el otro, de afectado. Las cláusulas no transactivas son aquellas que poseen un solo participante — agente o afectado- asociado a un proceso. Por último, se postula un tercer tipo de cláusula, llamada relacional, que establece una relación entre una entidad relacionante y otro elemento: las relacionales ecuativas sirven para establecer una identificación entre ambos elementos, las atributivas le adscriben características a la entidad relacionante, las posesivas indican una relación de posesión, y las locativas vinculan a la entidad con sus circunstancias espaciales.

Los procesos transactivos muestran una diferencia entre entidades que poseen agentividad y aquellas que no. La posibilidad de actuar sobre otras entidades o sobre otras personas es una indicación de poder. La causalidad en las cláusulas transactivas es clara, pero no lo es en las cláusulas no transactivas. Por lo tanto, los modelos no transactivos pueden generar cierta confusión en tanto, en algunos casos, no queda claro si la entidad involucrada es actor o afectado. 
Complementamos el análisis con la Teoría de la Valoración (Martin y White, 2005). Esta teoría describe y explica los sistemas de opciones semánticas que ofrece el lenguaje para evaluar, adoptar posiciones, negociar relaciones y construir personas textuales. En particular, se ocupa de la expresión lingüística de la actitud y la emoción, así como de los recursos que permiten al hablante variar el grado de compromiso que tiene con su emisión. En este trabajo, nos centramos en el subsistema de la actitud, que permite dar cuenta de la forma en que se inscriben las subjetividades en los textos. La actitud abarca tres regiones semánticas (v. Tabla 1) el afecto da cuenta de las emociones positivas y negativas que expresan los actores sociales; el juicio se refiere a las valoraciones sobre los comportamientos de las personas; y la apreciación supone la evaluación de fenómenos naturales y productos sociales.

TABla i: Subsistema de la ACTITUd

\begin{tabular}{|c|c|c|}
\hline \multirow[t]{4}{*}{ Afecto } & \multicolumn{2}{|l|}{ Inclinación } \\
\hline & \multicolumn{2}{|l|}{ Felicidad } \\
\hline & \multicolumn{2}{|l|}{ Seguridad } \\
\hline & \multicolumn{2}{|l|}{ Satisfacción } \\
\hline \multirow[t]{5}{*}{ Juicio } & \multirow[t]{3}{*}{ Estima social } & Normalidad (¿cuán excepcional?) \\
\hline & & Capacidad (¿cuán capaz?) \\
\hline & & Tenacidad (¿cuán resuelto?) \\
\hline & \multirow[t]{2}{*}{ Sanción social } & Propiedad (¿cuán ético?) \\
\hline & & Veracidad (¿cuán veraz?) \\
\hline \multirow[t]{3}{*}{ Apreciación } & \multicolumn{2}{|l|}{ Reacción } \\
\hline & \multicolumn{2}{|l|}{ Composición } \\
\hline & \multicolumn{2}{|l|}{ Evaluación } \\
\hline
\end{tabular}

\section{El kirchnerismo}

Néstor Kirchner fue un político argentino perteneciente al Movimiento Peronista, el cual toma su nombre del líder político Juan Domingo Perón, presidente de la República Argentina en tres ocasiones: 1946-1952, 1952-1955, 1973-1974. Kirchner asume la presidencia de la República Argentina el 25 de mayo de 2003, luego de haber sacado tan solo el 22, 24\% de votos. Desde ese entonces, el gobierno fue consciente de que debía 
construir una legitimidad que no le habían otorgado los comicios y buscó ampliar su base de apoyo a través de la incorporación de actores sociales de otros partidos políticos - lo que se conoció como la transversalidad- y con la convocatoria a los jóvenes. Así se construyó dentro del Movimiento Peronista un espacio político diferenciado: el kirchnerismo. En el año 2007, Cristina Fernández, esposa del ex presidente, asume por primera vez la presidencia con el 45,29\% de los votos. Su segundo mandato comenzó en el 2011, tras ganar los comicios con el 54,11\%, y finalizó en diciembre del 2015.

La Cámpora es una agrupación política juvenil que comienza a organizarse a fines del año 2006. En el 2008, sus militantes realizan las primeras apariciones públicas y, a partir de ese momento, comienzan a tener un papel cada vez más importante dentro de la escena política Argentina actual. No se trata de una agrupación juvenil más, sino de una organización gestada desde el propio gobierno de Néstor Kirchner y Cristina Fernández, con el objetivo de que organice y articule una militancia juvenil propiamente kirchnerista en todo el país. A lo largo de los años, se constituyó, además, en un actor político omnipresente en el discurso de los medios y de políticos tanto kirchneristas como de otras fuerzas políticas. Si bien existen algunos trabajos provenientes de la comunicación social y el periodismo no académico (Di Marco, 2012; Russo, 2014; Natanson, 2012), no hay, en la actualidad, investigaciones centradas en La Cámpora desde el punto de vista del análisis del discurso. Es por ello que consideramos relevante el desarrollo de un estudio lingüístico-discursivo que nos permita comprender qué representaciones sociales puso en circulación La Cámpora respecto a la militancia juvenil.

El corpus de la investigación general se compone de treinta y un editoriales tomados de la página web de La Cámpora (www.lacampora.org - fecha de consulta marzo de 2012) y doce discursos públicos de Cristina Fernández, entre los años 2008 y 2011 (www. casarosada.gov.ar - fecha de consulta abril de 2013). En este artículo, seleccionamos dos editoriales que consideramos representativos de los fenómenos examinados en el corpus completo y que sirven para ilustrar, a través de un análisis cualitativo en profundidad, las conclusiones obtenidas en nuestra investigación.

\section{Análisis}

\subsection{Editorial del 22 de abril de 2009}

En este editorial, se presenta como factor detonante del interés juvenil por la política a un sujeto individual, Néstor Kirchner ${ }^{1}$. Luego, se consideran también como factores

1. La visión personalista para justificar la militancia se repite en los editoriales del 2 y del 27 de noviembre del año 2010. 
la incidencia del proyecto colectivo kirchnerista y la amenaza del retorno a la política/ negocio de los años $90^{2}$.

El único proceso realizado por Néstor Kirchner marca la capacidad y la propiedad ética del ex presidente y lo plantea como disparador del interés de los jóvenes por la política: "A partir del 25 de mayo del 2003, el entonces presidente de la Nación, Néstor Kirchner, comenzó a devolverle significado a la política" (destacado nuestro). Sin embargo, no se quedan en una postura personalista y el resto de los procesos se refieren a abstracciones colectivas como "la política", "el proyecto", "el campo nacional y popular". En la Tabla 2 , presentamos los procesos realizados por el "proyecto kirchnerista".

TAbla 2: Sistema ACCional gobierno - Editorial i

\begin{tabular}{|l|l|l|l|l|}
\hline \multicolumn{1}{|c|}{ Actor } & \multicolumn{1}{|c|}{ Proceso } & \multicolumn{1}{|c|}{$\begin{array}{c}\text { Afectado } \\
\text { (meta) }\end{array}$} & $\begin{array}{c}\text { Afectado } \\
\text { (beneficiario) }\end{array}$ & Circunstancias \\
\hline la política & fue recuperando & $\begin{array}{l}\text { su lugar y } \\
\text { su sentido }\end{array}$ & ---- & \\
\hline $\begin{array}{l}\text { un proyecto } \\
\text { político claro }\end{array}$ & devolvió & su lugar & $\begin{array}{l}\text { a la otra palabra } \\
\text { (lealtad) }\end{array}$ & básicos \\
\hline $\begin{array}{l}\text { un proyecto } \\
\text { político claro }\end{array}$ & establecía & $\begin{array}{l}\text { la soberanía } \\
\text { política y la } \\
\text { independencia } \\
\text { económica }\end{array}$ & ---- & como pilares \\
\hline el proyecto & recuperar & la justicia social & & \\
\hline $\begin{array}{l}\text { por este } \\
\text { proyecto }\end{array}$ & convocados & $\begin{array}{l}\text { miles de } \\
\text { militantes }\end{array}$ & le / al pueblo & \\
\hline este proyecto & devolver & la dignidad & & \\
\hline $\begin{array}{l}\text { ese campo } \\
\text { nacional y } \\
\text { popular }\end{array}$ & recuperó & la política & & \\
\hline
\end{tabular}

2. En diez editoriales del corpus se detecta una oposición explícita entre gobierno kirchnerista y gobierno de los ańos 90. Esta oposición suele marcar el carácter (re)fundacional del kirchnerismo. En los editoriales del 22 de abril de 2009, 26 de octubre de 2009, 28 de diciembre de 2009, 2 de noviembre de 2009, 12 de septiembre de 2010, 27 de noviembre de 2010 y 4 de julio de 2011 esta oposición, además, es vinculada con las razones que motivaron a los jóvenes actuales a militar. 
La objetivación ${ }^{3}$ del "proyecto" no solo es agente de una serie de procesos materiales y verbales considerados éticamente apropiados, sino que se presenta como aquel que hizo sentir a los jóvenes interpelados ("miles de militantes nos vimos convocados por este Proyecto") para actuar en política.

"Devolver" y "recuperar" son los dos procesos que se repiten y que activan un mismo campo de sentido: se recupera o se devuelve aquello que se perdió o fue robado. La idea de robo aparece en este discurso y, si bien no se indican los participantes agentivos del acto de robar, la temporalización alude a los posibles responsables: "frente al saqueo de la Patria durante la década neoliberal". Como dijimos, la idea de recuperación y devolución de (el sentido de ${ }^{4}$ ) la política supone una pérdida anterior. Por lo tanto, las representaciones de La Cámpora se encuentran en correlación con aquellas que presentan a la década del 90 como una década de inactividad política ("antipolítica"), sobre todo por parte de los jóvenes, y de robo material pero también simbólico hacia el pueblo por parte de empresas y políticos.

Los vínculos entre política y medios en los 90 son caracterizados a través de los campos conceptuales presentados en la Tabla 3, todos valorados negativamente.

Tabla 3: Campos conceptuales

\begin{tabular}{|l|l|}
\hline Servidumbre/dominación & partidocracia servil, estigmatizada, condenada, arrodillarla \\
\hline Robo & saqueo, te apropias, despojas \\
\hline Magia/religión & los gurues, verdades reveladas \\
\hline Política como negocio & socios de turno, mercantilizaron la política \\
\hline Bajo como negativo & $\begin{array}{l}\text { llevar a la Argentina, no a las puertas sino al corazón del } \\
\text { abismo... }\end{array}$ \\
\hline
\end{tabular}

3. Según van Leeuven (2008), los actores sociales pueden ser impersonalizados, por ejemplo, a través de sustantivos abstractos o sustantivos concretos cuyo significado no incluye el rasgo semántico [+ humano]. La objetivación ocurre cuando los actores sociales son representados a través de la referencia a un lugar o cosa cercanamente asociado a la persona o a la acción que están llevando a cabo. Es decir, se lleva a cabo a través de una metonimia.

4. La política kirchnerista es caracterizada por la militancia, la lealtad y, además, es construida como un signo, como semiotizada (tiene sentido, significado).

5. La vinculación de los políticos (de los años 90 o actuales) no kirchneristas con empresas y con el ámbito de los negocios es una constante en el corpus analizado (editoriales del 14 de marzo de 2009, 20 de marzo de 2009, 7 de abril de 2009, 13 de abril de 2009, 23 de junio de 2009, 26 de octubre de 2009, 28 de diciembre de 2009, 12 de septiembre de 2010, entre otros). 
A continuación presentamos algunos ejemplos:

(1) La economía, los gurúes, tecnócratas y demás verdades reveladas del mercado, se fueron transformando en piezas de museo.

(2) De la hecatombe del 2001, hay un elemento que el poder económico ańora y pretende revivir constantemente: la antipolítica.

(3) La otra palabra estigmatizada y condenada a los márgenes en la noche de los '90: la militancia.

(4) Sabemos que los grupos económicos creían haberla [la palabra "lealtad"] erradicado cuando mercantilizaron la política con la complicidad de muchos políticos.

Este grupo de cláusulas hace referencia explícita a las acciones de los actores económicos, pero se puede incluir a los políticos neoliberales de la década de los 90 a partir de referencias más difusas como "tecnócratas", la temporalización "en la noche de los 90" y la instrumentalización/nominalización "con la complicidad de muchos políticos". El poder político y económico es representado como actor de procesos materiales y verbales valorados negativamente desde el punto de vista de la propiedad ética y de la veracidad.

Los ejemplos anteriores muestran que los políticos y empresarios de la década del 90 han sido desplazados por el kirchnerismo, pero también marcan una voluntad de recuperación de esos espacios y del poder perdido. Así, la activación política de los jóvenes no solo se debe a la atracción que les genera el proyecto encabezado por Kirchner y Fernández, sino que constituye una reacción a los poderes de los años 90. El kirchnerismo es presentado como el actor social que se encargó de combatir aquellos poderes injustos con los que los jóvenes crecieron ("se fueron transformando en piezas de museo"). Algunos de esos poderes fueron derrotados por "el proyecto", pero otros resisten o intentan volver: "hay un elemento que el poder económico añora y pretende revivir". Esa amenaza latente de los poderes políticos y económicos pasados justifica la voluntad de los jóvenes de participar en política, como defensores de los cambios conseguidos por el kirchnerismo. Así, refiriéndose a la voluntad de poder de una de las empresas de multimedios del país, el Grupo Clarín, expresan: “¿Qué esperás? ¿Qué nos sentemos a ver cómo te apropias de la palabra monopolizándola? ¿Qué desperdiciemos otros 30 ańos por tu capricho?”

¿Cuál es el rol de los jóvenes militantes frente a la situación hasta aquí descripta? En las tablas 4, 5 y 6, podemos ver los procesos en los cuales participan en el rol de actores. 
TAbla 4: Sistema accional Militantes - Editorial I

Procesos mentales

\begin{tabular}{|c|c|c|c|}
\hline Actor & Proceso & Afectado & Circunstancias \\
\hline miles de militantes & vimos & nos & \\
\hline (jóvenes argentinos/nos) & viendo & tu ficción & \\
\hline (jóvenes argentinos/nos) & vimos & te & \\
\hline (miles de jóvenes/nos) & no escuchamos & tu denuncia & $\begin{array}{l}\text { frente al saqueo } \\
\text { de la Patria durante } \\
\text { la década neoliberal }\end{array}$ \\
\hline (miles de jóvenes/nos) & vimos & te & \\
\hline (miles de jóvenes/nos) & vemos & $\begin{array}{l}\text { la oportunidad } \\
\text { histórica de... }\end{array}$ & en este proyecto \\
\hline (nosotros) & ver & $\begin{array}{l}\text { como te apropias } \\
\text { de la palabra } \\
\text { monopolizándola }\end{array}$ & \\
\hline nosotros & queremos & $\begin{array}{l}\text { una Argentina } \\
\text { Grande y un } \\
\text { Pueblo Feliz }\end{array}$ & \\
\hline (nosotros) & no renunciamos & a eso & \\
\hline $\begin{array}{l}\text { (un grupo de militantes } \\
\text { de ese campo nacional } \\
\text { y popular) }\end{array}$ & decidió & $\begin{array}{l}\text { comenzar a } \\
\text { trabajar... }\end{array}$ & \\
\hline (nosotros) & decidimos & tomar... & \\
\hline (nosotros) & sabemos & $\begin{array}{l}\text { la palabra te } \\
\text { duele (lealtad) }\end{array}$ & \\
\hline (nosotros) & sabemos & $\begin{array}{l}\text { los grupos } \\
\text { económicos creían } \\
\text { haberla [la palabra } \\
\text { lealtad] erradicado }\end{array}$ & \\
\hline nosotros & sentíamos & $\begin{array}{l}\text { que ese era } \\
\text { el nombre }\end{array}$ & \\
\hline (nosotros) & sońamos & construir & \\
\hline
\end{tabular}




\begin{tabular}{|c|c|c|c|}
\hline (nosotros) & sabemos & $\begin{array}{l}\text { que nuestro país } \\
\text { no es el mismo } \\
\text { que aquel }\end{array}$ & \\
\hline (nosotros) & queremos & $\begin{array}{l}\text { que a los } \\
\text { argentinos no } \\
\text { nos pase más... }\end{array}$ & sencillamente \\
\hline (nosotros) & no queremos & esas cosas & más \\
\hline (nosotros) & queremos & $\begin{array}{l}\text { un pueblo } \\
\text { consciente y } \\
\text { organizado }\end{array}$ & \\
\hline (nosotros/la cámpora) & pretendemos & $\begin{array}{l}\text { la felicidad de } \\
\text { nuestro Pueblo } \\
\text { y la grandeza de } \\
\text { nuestra Nación. }\end{array}$ & $\begin{array}{l}\text { junto a otras } \\
\text { organizaciones } \\
\text { juveniles del } \\
\text { kirchnerismo, del } \\
\text { peronismo, de la } \\
\text { centro izquierda, de los } \\
\text { movimientos sociales, } \\
\text { del movimiento } \\
\text { obrero y de la cultura } \\
\text { en todo el país }\end{array}$ \\
\hline ---- & $\begin{array}{l}\text { tuvimos } \\
\text { que sufrir }\end{array}$ & nosotros & en el pasado reciente \\
\hline
\end{tabular}

TABla 5: Sistema ACCIONAL MILITANTES - EDITORIAL I

Procesos MATERIALES Y DE COMPORTAMIENTO

\begin{tabular}{|l|l|l|l|}
\hline \multicolumn{1}{|c|}{ Actor } & \multicolumn{1}{c|}{ Proceso } & \multicolumn{1}{c|}{ Afectado } & \multicolumn{1}{c|}{ Circunstancias } \\
\hline $\begin{array}{l}\text { la aparición de un } \\
\text { grupo de militantes } \\
\text { juveniles que } \\
\text { abrazamos la política } \\
\text { con real convicción }\end{array}$ & $\begin{array}{l}\text { ha puesto } \\
\text { en vilo }\end{array}$ & $\begin{array}{l}\text { al mayor grupo } \\
\text { económico- } \\
\text { mediático del país }\end{array}$ & \\
\hline (militantes juveniles) & abrazamos & la política & con real convicción \\
\hline v. pàg. 58-59 & devolver & la dignidad /al pueblo & \\
\hline (nosotros) & nos sentemos & ----- & por tu capricho \\
\hline (nosotros) & desperdiciemos & otros 30 años & \\
\hline
\end{tabular}




\begin{tabular}{|c|c|c|c|}
\hline $\begin{array}{l}\text { (un grupo de militantes } \\
\text { de ese campo } \\
\text { nacional y popular) }\end{array}$ & $\begin{array}{l}\text { comenzar a } \\
\text { trabajar }\end{array}$ & $\begin{array}{l}\text { en la organización de } \\
\text { esa fuerza nacida en el } \\
2003 \text {, de ese impulso } \\
\text { juvenil, de ese dato } \\
\text { nuevo de la política }\end{array}$ & \\
\hline (nosotros) & tomar & $\begin{array}{l}\text { el nombre de Héctor } \\
\text { J. Cámpora, un } \\
\text { símbolo de Lealtad }\end{array}$ & $\begin{array}{l}\text { con este grupo } \\
\text { de compañeros } \\
\text { decidimos en honor } \\
\text { a la Historia }\end{array}$ \\
\hline (nosotros) & construir & (aquello) & \\
\hline (nosotros) & hicimos & 10 carteles de cartón & \\
\hline nosotros & $\begin{array}{l}\text { seguir } \\
\text { trabajando }\end{array}$ & ---- & $\begin{array}{l}\text { por nuestro País, } \\
\text { por nuestro pueblo }\end{array}$ \\
\hline (nosotros) & $\begin{array}{l}\text { habíamos } \\
\text { perdido }\end{array}$ & la (militancia) & $\begin{array}{l}\text { en un país <que } \\
\text { se extravió> }\end{array}$ \\
\hline (nosotros) & defender & $\begin{array}{l}\text { un futuro / } \\
\text { para los argentinos }\end{array}$ & \\
\hline
\end{tabular}

TABla 6: Sistema ACCiONAl Militantes - EDitORIAL I

Procesos verbales

\begin{tabular}{|l|l|l|l|}
\hline \multicolumn{1}{|c|}{ Actor } & \multicolumn{1}{c|}{ Proceso } & \multicolumn{1}{c|}{ Afectado } & \multicolumn{1}{c|}{ Circunstancias } \\
\hline (nosotros) & refrendar & aquello & \\
\hline (nosotros) & podemos expresar & (la militancia) & $\begin{array}{l}\text { hoy } \\
\text { con la plena convicción... }\end{array}$ \\
\hline
\end{tabular}

Observamos que hay una amplia cantidad de procesos mentales de tipo perceptivo: los jóvenes ven, escuchan $-\mathrm{O}$ no- $\mathrm{y}$ sienten. También se indica una serie de intenciones o deseos, pero no queda en claro que se trate de acciones que efectivamente estén llevando —o intentando llevar - a la práctica: "Nosotros queremos una Argentina Grande y un Pueblo Feliz"; "un grupo de militantes de ese campo nacional y popular que recuperó la política, decidió comenzar a trabajar", "para refrendar aquello que soñamos construir..." (destacado nuestro). Los procesos materiales y de conducta no presentan acciones efectivas sino que se encuentran modalizados desde el punto de vista deóntico o volitivo.

La juventud posee la voluntad de hacer una serie de acciones que le confieren propiedad y tenacidad, pero no se puede hablar de capacidad más que en un sentido potencial. Con 
respecto a la valoración de la tenacidad, en varios casos se trata de nominalizaciones que la presuponen — “esa fuerza", "impulso juvenil”—y, en otros, de una tenacidad más difusa que no refiere a sus acciones sino a sus deseos, porque, otra vez, no hay ninguna indicación de que estén haciendo algo para concretarlos: "Nosotros queremos una Argentina Grande y un Pueblo Feliz. A eso no renunciamos" (el destacado es nuestro).

\subsection{2 de septiembre de 2010}

En este editorial, aparece un elemento recurrente de los textos de La Cámpora, la clasificación del momento histórico argentino de los últimos años como "crucial"6. La excepcionalidad de la coyuntura requiere que todos tomen partido. Si antes había apatía por parte de los jóvenes ahora no puede haberla. El texto lo plantea de forma casi imperativa: "Que cada cual elija su lugar en este momento crucial de la vida nacional" (destacado nuestro).

La trascendencia del momento histórico refiere a la presencia del kirchnerismo en el gobierno y es lo que justifica el interés político de la juventud. En un primero momento, la razón es circular: los jóvenes se interesan en el proyecto, porque fue el único que se interesó en ellos. Sin embargo, en seguida ese interés del gobierno en los jóvenes se traduce en una enumeración de medidas que fueron tomadas en su beneficio: "Este es el único proyecto que vuelve a creer en nosotros apostando a la defensa de los derechos humanos, al trabajo, a la Asignación Universal por Hijo, a la salud y a la educación para una mejor distribución que garantice una mayor inclusión social en la Argentina” (destacado nuestro). El proceso de comportamiento "apostar" no deja en claro si se trata, en todos los casos, de logros concretos (juicio de capacidad) del kirchnerismo o de una disposición mental, una inclinación del proyecto por las áreas nombradas. En todos los casos la valoración resaltada es la propiedad ética.

Se activa, una vez más, el campo semántico de la pérdida (que podría implicar también el del robo, como en el editorial anterior): "la realidad efectiva que nuestro pueblo nunca debió perder", "Es por eso que, hemos decidido acompañar al hombre y a la mujer que nos han devuelto la esperanza", "esa esperanza recuperada" (destacado nuestro). La cuestión de la devolución se puede vincular también con las imágenes de "vuelta" o "regreso" que instala La Cámpora: "Este es el único proyecto que vuelve a creer en nosotros" (destacado nuestro). "Devolver", "recuperar y "volver a creer" hacen referencia a un estado anterior que fue perdido o usurpado y que, con el kirchnerismo, se restauraría. Esto último implica que antes algún proyecto ya había creído en los jóvenes. Esa referencia a "nosotros" es problemática, es posible que otros políticos hayan creído en otros jóvenes pero no

6. La definición del momento histórico como crucial aparece en los siguientes editoriales de la agrupación: 13 de abril de 2009, 23 de junio de 2009, 9 de julio de 2009, 28 de diciembre de 2009, 12 de septiembre de 2010 y 2 de noviembre de 2010. Justifica que los jóvenes ya no puedan mantenerse alejados de la política. 
en quienes escriben este editorial en tanto se presentan como la nueva generación que emerge ahora: "El 14 de septiembre el Luna Park y sus inmediaciones verán emerger a una nueva generación militante".

El rol de los líderes — "el hombre" y "la mujer" — los coloca en un lugar de capacidad mayor que la del pueblo, quienes no habían podido recuperar "la realidad efectiva" o "la esperanza”. Esto deja al pueblo, militantes incluidos, en una posición dependiente de los políticos.

Junto con la convocatoria realizada por el kirchnerismo, la militancia se explica, también, como reacción al rol pasivo que pretenden otorgarles los medios de comunicación a los jóvenes: "Los jóvenes no queremos ser parte de una generación testigo de la autocompasión impulsada a través del discurso mediático hegemónico" (destacado nuestro). Los medios concentrados vuelven a presentarse como enemigos que buscan acabar con el kirchnerismo.

Se activa, además, parte del imaginario épico presente en los discursos de La Cámpora (Flax, 2015), en este caso a través de la representación de la política como sacrificio. Los militantes se construyen como dispuestos a compartir ese sacrificio con los líderes, constituyendo juicios de propiedad ética y tenacidad sobre la juventud: "El 14 de septiembre el Luna Park y sus inmediaciones verán emerger a una nueva generación militante dispuesta a compartir ese sacrificio con Ud. y la Compañera Presidenta, para que todos juntos juremos 'CON GLORIA VIVIR'” (destacado nuestro). Sin embargo, el sacrificio con respecto a los jóvenes no se encuentra en el plano de la realidad, sino de la inclinación: "dispuesta a".

A diferencia del editorial anterior, el rol de los jóvenes no se construye a partir de lo que quieren hacer, sino de lo que quieren ser. Sin embargo, se mantienen, al igual que en el texto del 22 de abril de 2009, en el plano de la potencialidad y no de lo que son efectivamente. Podemos encontrar definiciones presentadas a partir de cláusulas relacionales identificativas — todas modalizadas — que marcan más una intención que una identidad conseguida ("no queremos ser”, "queremos ser”, “dejar de ser”). Una vez más, en el discurso de La Cámpora nos encontramos en el ámbito de la volición y no de la concreción(v. tabla 7).

TABla 7: Sistema Relacional - EDitorial 2

\begin{tabular}{|l|l|l|}
\hline Entidad relacionante & \multicolumn{1}{|c|}{ Procesos } & \multicolumn{1}{c|}{ Identificador } \\
\hline los jóvenes & no queremos ser & $\begin{array}{l}\text { parte de una generación testigo } \\
\text { de la autocompasión }\end{array}$ \\
\hline los jóvenes & queremos ser & sujeto político \\
\hline los jóvenes & dejar de ser & objeto de consumo y represión \\
\hline este & es & el único proyecto \\
\hline
\end{tabular}


En las tablas 8, 9 y 10, presentamos los procesos que tienen a los jóvenes, calificados como compañeros, militantes o nueva generación militante, como participantes agentivos.

TABLA 8: SisTEMA ACCIONAL MILITANTES - EDITORIAL 2

Procesos mentales

\begin{tabular}{|l|l|l|}
\hline \multicolumn{1}{|c|}{ Actor } & \multicolumn{1}{c|}{ Proceso } & \multicolumn{1}{c|}{ Afectado } \\
\hline (nosotros) & sabíamos & los / cobardes \\
\hline (nosotros) & nunca (sabíamos) & (los) ruines \\
\hline (nosotros) & sabemos & que "vivir solo cuesta vida" \\
\hline
\end{tabular}

TABla 9: Sistema ACCiOnal Militantes - EDitorial 2

Procesos Verbales

\begin{tabular}{|l|l|l|l|}
\hline \multicolumn{1}{|c|}{ Actor } & \multicolumn{1}{c|}{ Proceso } & \multicolumn{1}{c|}{ Tema } & \multicolumn{1}{c|}{ Afectado } \\
\hline (Los compañeros) & Dicen & Cláusulas siguientes & x \\
\hline Todos & Juremos & Cláusula siguiente & x \\
\hline
\end{tabular}

TAbla io: Sistema aCcional militantes - editorial 2

Procesos MATERIALES Y DE COMPORTAMIENTO

\begin{tabular}{|l|l|l|l|}
\hline \multicolumn{1}{|c|}{ Actor } & \multicolumn{1}{|c|}{ Proceso } & \multicolumn{1}{c|}{ Afectado } & \multicolumn{1}{c|}{ Afectado } \\
\hline (los mismos compañeros) & trabajaron & --- & \\
\hline (los mismos compañeros) & siguen haciendo & lo (trabajar) & su lugar \\
\hline cada cual & elija & $\begin{array}{l}\text { en este momento } \\
\text { crucial de la } \\
\text { vida nacional }\end{array}$ \\
\hline (nosotros) & $\begin{array}{l}\text { hemos decidido } \\
\text { acompañar }\end{array}$ & $\begin{array}{l}\text { al hombre y } \\
\text { a la mujer }\end{array}$ & $\begin{array}{l}\text { es por eso } \\
\text { que... } x\end{array}$ \\
\hline
\end{tabular}




\begin{tabular}{|l|l|l|l|}
\hline $\begin{array}{l}\text { la movilización y organización } \\
\text { de miles de militantes, } \\
\text { adherentes y simpatizantes } \\
\text { jóvenes a lo largo y a lo } \\
\text { ancho de la Patria }\end{array}$ & aportarán & $\mathrm{x}$ & $\mathrm{x}$ \\
\hline $\begin{array}{l}\text { (una nueva generación } \\
\text { militante) }\end{array}$ & $\begin{array}{l}\text { está dispuesta } \\
\text { a compartir }\end{array}$ & ese sacrificio & $\begin{array}{l}\text { con Ud. y la } \\
\text { Compañera } \\
\text { Presidente }\end{array}$ \\
\hline (todos) & vivir & --- & con gloria \\
\hline
\end{tabular}

A diferencia del editorial anterior, vemos que predominan los procesos materiales y de comportamiento por encima de los mentales. Sin embargo, una vez más, todos se encuentran modalizados con excepción del verbo sumamente inespecífico "trabajaron". Las nominalizaciones que aparecen en el texto implican que los jóvenes se movilizaron y organizaron. Con lo cual, su rol parecería recaer en la movilización y en la organización de actos como el que se nombra en el propio editorial que tendrá lugar el 14 de septiembre de 2010. Las dos nominalizaciones son, a su vez, el agente de un proceso material diferido al futuro que, si bien considera a los militantes como los agentes reales que “aportarán”, no especifica qué es lo que aportarían o a quién, aunque si se especifica para qué: "la movilización y organización de miles de militantes, adherentes y simpatizantes jóvenes a lo largo y a lo ancho de la Patria, aportarán para que esa esperanza recuperada, se transforme de una vez y para siempre en la realidad efectiva”.

Por último, como dijimos más arriba, una acción que plantea la política en términos de sacrificio se atribuye a los jóvenes aunque también se encuentra modalizada y lo que se afirma es la valoración de inclinación: "dispuesta a compartir ese sacrificio"7.

\section{Consideraciones finales}

A lo largo de este trabajo, profundizamos en las razones que la agrupación La Cámpora expone para la masiva confluencia de jóvenes al kirchnerismo durante los últimos años. Para ello, analizamos un corpus de treinta y un editoriales a través de una metodología cualitativa de análisis. Para la ilustración de los resultados, seleccionamos - por su representatividad — dos de los textos analizados.

Observamos que la primera razón para militar en el kirchnerismo es muy simple: ellos se acercan al kirchnerismo, porque este los convocó —o, al menos, así lo percibieron ellos - a militar. Es decir, es el único proyecto político que se interesó por los jóvenes y

7. En todo el corpus analizado, prevalecen los procesos mentales o perceptivos y los procesos materiales potenciales (en tiempo futuro, modalidad deóntica o modalidad volitiva) por sobre los procesos concretamente realizados. 
los señala como actores sociales importantes, a diferencia de otros políticos — sobre todo en los ańos 90- que los ignoraban.

La segunda razón radica en los cambios introducidos por el kirchnerismo con respecto a la política neoliberal de los ańos 90, caracterizada por los negocios, el saqueo, la democracia condicionada, la tecnocracia, la relegación del pueblo y la estigmatización de la militancia. Muchos de esos cambios se refieren específicamente a áreas de interés de los jóvenes, como la educación, el trabajo, los subsidios por hijos pequeños, etc. Aquí se activa el campo semántico del robo y el saqueo, a partir de la insistencia en procesos como "devolver" y "recuperar" referidos al gobierno de Kirchner.

Sin embargo, no son solo las acciones positivas realizadas por el kirchnerismo lo que lleva a los jóvenes a movilizarse, sino la amenaza que suponen los intereses políticos y, sobre todo, los económicos que fueron o están siendo desplazados por los gobiernos de Kirchner y Fernández, y que quieren retrotraer la situación del país. Así, la frustración que les generaban las acciones de políticos y empresarios durante el gobierno del presidente Menem (1989-1999) y la amenaza de su retorno constituyen otro factor para la masificación de la militancia juvenil.

El único rol agentivo que poseen los jóvenes, en el primer editorial, se vincula con la conceptualización de la política como lucha: los jóvenes deben luchar y resistir contra los poderes que amenazan al proyecto kirchnerista. En otras palabras, no son agentes de cambio - ese rol queda para los políticos adultos - si no que son los defensores que deben lograr mantener lo conseguido hasta el momento. En este sentido, se valoran básicamente a través de juicios de tenacidad. En el segundo editorial, su agentividad pasa por un lugar común a cualquier militancia juvenil: la movilización y organización de actos. El resto de los procesos, postulan a los militantes de La Cámpora en roles perceptivos y volitivos que muestran su comprensión de la particularidad histórica, pero que plantean su accionar en términos de voluntad, más que en acciones concretamente realizadas. Las acciones materiales suelen estar modalizadas, refiriendo a las intenciones o al querer hacer más que al hacer mismo. En este sentido refuerzan las miradas adultocéntricas que consideran a los jóvenes como personas en proceso de formación/ preparación cuyo rol se encuentra desplazado a hacia el futuro.

\section{Referencias}

Bonvillani, A., Palermo, A., Vázquez, M., y Vommaro, P. (2010). Del Cordobazo al kirchnerismo. Una lectura crítica acerca de los períodos, temáticas y perspectivas en los estudios sobre juventudes y participación política en la Argentina. En S. Alvarado y P. Vommaro. (Eds.), Jóvenes, cultura y politica en América Latina. Algunos trayectos de relaciones, experiencias y lecturas (1960-2000) (pp. 21-54). Rosario: Homo Sapiens Ediciones.

Di Marco, L. (2012). La Cámpora. Buenos Aires: Sudamericana. 
Fairclough, N. (1992). Discourse and social change. Cambridge: Polity Press.

Fairclough, N. (2003a). El análisis crítico del discurso como método para la investigación en ciencias sociales. En M. Meyer y R. Wodak. (Eds.), Métodos del análisis crítico del discurso (pp. 179-204). Barcelona: Gedisa.

Fairclough, N. (2003b). Analysing discourse. Textual analysis for social research. London: Routledge.

Fairclough, N. (2005). Critical discourse analysis. Marges linguistiques, 9, 76-94.

Fairclough, N. y Wodak, R. (2000). Análisis crítico del discurso. En T. van Dijk. (Ed.), El discurso como interacción social. Estudios sobre el discurso II. Una introducción multidisciplinaria (pp. 367-404). Barcelona: Gedisa.

Flax, R. (2015). La construcción de la identidad de la juventud kirchnerista a partir de su relato de la historia. En N. Gregori Torada e I.Martínez Gordo. (Eds.), Actas de IX Conferencia Internacional de Lingüistica (pp. 211-225). La Habana: Instituto de Literatura y Lingüística de la Universidad de La Habana.

Fowler, R., Hogde, R., Gunther, K. y Trew, T. (1983). Lenguaje y control. México: Fondo de cultura económica.

Hodge, R., y Kress, G. (1979). Language as Ideology. Londres: Routledge \& Kegan Paul Books.

Kaplan, N. (2004). Nuevos desarrollos en el estudio de la evaluación en el lenguaje: la teoría de la valoración. Boletín de Lingüistica, 22, 52-78.

Kriger, M. (2011). La invención de la juventud, entre la muerte de las naciones y su resurrección (Material confeccionado para curso de posgrado). Recuperado de http://www.cursoscaicyt.gov.ar

Martin, J. y White, P. (2005). The language of evaluation. Appraisal in English. Nueva York: Palgrave Macmillan.

Natanson, J. (2012). ¿Por qué los jóvenes están volviendo a la politica? De los indignados a La Cámpora. Buenos Aires: Debate.

Russo, S. (2014). Fuerza propia, La Cámpora por dentro. Buenos Aires: Debate. van Dijk, T. (2005). Política, ideología y discurso. Quórum Académico, 2(2), 17-47. van Leeuwen, T. (2008). Discourse and practice. New tools for critical discourse analysis. Oxford: Oxford University Press.

\section{Corpus}

La Cámpora, editorial del 22 de abril de 2009. Recuperado de http://www.lacampora.org/2010/09/12/ahora-mas-que-nunca/

La Cámpora, editorial del 12 de septiembre de 2010. Recuperado de http://www.lacampora.org/2009/04/22/\%c2\%bfpor-que-estas-tan-nervioso/ 